\title{
An assessment of the isoniazid preventive therapy programme for children in a busy primary healthcare clinic in Nelson Mandela Bay Health District, Eastern Cape Province, South Africa
}

\author{
F Black, ${ }^{1} \mathrm{MB}$ ChB, MPhil (Maternal and Child Health); F Amien, ${ }^{2} \mathrm{BChD}, \mathrm{MChD}$ (Community Dentistry); J Shea, ${ }^{1}$ MSc, HPE \\ ${ }^{1}$ Department of Paediatrics and Child Health, Child Health Unit, Faculty of Health Sciences, University of Cape Town, South Africa \\ ${ }^{2}$ School of Public Health and Family Medicine, Faculty of Health Sciences, University of Cape Town, South Africa
}

Corresponding author: F Black (fayeblack@gmail.com)

\begin{abstract}
Background. Tuberculosis (TB) is a significant contributor to the international and national burden of disease. Global estimates suggest that there were 10.4 million new cases of TB in 2015. Children accounted for $\sim 10 \%$ of these cases, although in South Africa (SA) this figure is thought to be higher. Despite clear evidence that isoniazid preventive therapy (IPT) can reduce the risk of progression from TB infection to disease in TB contacts, IPT has been poorly implemented in SA national TB control programmes.

Objectives. To determine current practices regarding the identification and management of child contacts ( $<5$ years of age) at a primary care clinic in the Nelson Mandela Bay Health District, Eastern Cape Province, SA.

Methods. A cross-sectional descriptive study was conducted using a retrospective record review of infectious TB index patients aged $\geq 15$ years. Folders of index patients with bacteriologically confirmed pulmonary TB, who started TB treatment between 21 October 2011 and 28 February 2014, were included. A sample size of 246 child contacts was required to obtain adequate power. A $95 \%$ confidence interval (CI) was used to determine statistically significant results.

Results. Index patient records ( $N=491)$ were assessed and 261 child contacts identified. In a high percentage of index patient folders (87.5\%; $n=430$ ), contacts were documented, although only 0.53 child contacts were identified per index patient. Of the 261 child contacts identified, 184 (70.5\%) were screened for TB, 2 started TB treatment and 108/184 (58.7\%) started IPT. For the remaining 74 (40.2\%) children, there was no documentation of further management. Only 4 (3.7\%) children completed the 24-week IPT course. Male patients reported fewer child contacts $\left(\chi^{2}=7.31 ; p=0.01\right.$; odds ratio (OR) $0.6 ; 95 \%$ CI $\left.0.42-0.86\right)$ and were less likely to bring contacts for screening $\left(\chi^{2}=8.98 ; p=0.003\right.$; OR 0.41 ; $95 \%$ CI 0.24 - 0.72). Retreatment index patients were also less likely to bring contacts for screening $\left(\chi^{2}=6.37 ; p=0.01 ;\right.$ OR $0.45 ; 95 \%$ CI 0.25 $0.81)$ and those who were screened were less likely to initiate IPT ( $\chi^{2}=4.05 ; p=0.04$; OR $0.54 ; 95 \%$ CI $\left.0.3-0.95\right)$.

Conclusion. Despite contacts being well documented, child contacts were poorly identified. The fall-out of children at each step from identification to IPT completion was unacceptably high. Contacts of male patients and retreatment index patients were at greater risk of poor management. Recommendations to improve IPT delivery at national and local level include a review of the national IPT guidelines, considering the relative success of shorter courses of TB prophylaxis, the use of standardised IPT stationery, staff training and the involvement of community health workers in contact management.
\end{abstract}

S Afr Med J 2018;108(3):217-223. DOI:10.7196/SAMJ.2018.v108i3.12639

Tuberculosis (TB) is a significant contributor to the international and national burden of disease. In 2015, there were an estimated 10.4 million new cases of TB globally; South Africa (SA) ranked among the top six countries, accounting for $60 \%$ of the total number of new cases. ${ }^{[1]}$ Although SA managed to curb its TB incidence to 860/100 000 in 2013, ${ }^{[2]}$ TB in the Nelson Mandela Bay Health District (NMBHD) remains rampant, with an incidence of $949.3 / 100000 .{ }^{[3]}$ It has consequently been identified as one of four TB crisis districts in the country. ${ }^{[4]}$ The burden of childhood TB is substantial. The World Health Organization (WHO) estimates that childhood TB accounts for $\sim 10 \%$ of the total number of TB cases worldwide, although in high-burden areas the incidence has been shown to be significantly higher. ${ }^{[2]}$ In the past, childhood TB has been overlooked as a health priority. The focus of global public health campaigns to control TB has been to reduce transmission by early case-finding and treatment of highly infectious patients. ${ }^{[5]}$ As children often have paucibacillary $\mathrm{TB}$, their risk of transmission is low and, thus, they have largely gone unnoticed.
The burden of childhood TB can be greatly reduced by active contact tracing and diligent prescribing of chemoprophylaxis to patients in whom active TB has been excluded. ${ }^{[6]}$ The rationale behind contact screening is twofold. Firstly, it provides TB preventive therapy to high-risk individuals, such as young children and HIV-infected individuals. Secondly, it actively traces contacts who have TB and treats them appropriately. ${ }^{[7]}$ A 6 - 9-month course of isoniazid preventive therapy (IPT) can diminish the risk of developing TB disease by two-thirds; with good compliance this benefit may be increased to almost $90 \% .{ }^{[8]}$ The National Department of Health (NDoH) has developed TB control programme guidelines for the management of child contacts (Fig. 1). Since 2008, these guidelines have recommended a symptom-based screening approach that does not require a skin test or chest radiograph in an asymptomatic child, as recommended in earlier guidelines..$^{[9]}$

However, contact tracing, screening and IPT initiation have been poorly implemented in areas of $\mathrm{SA}^{[10-15]}$ and other low- and middleincome countries. ${ }^{[16-19]}$ In Malawi, operational challenges such as high 


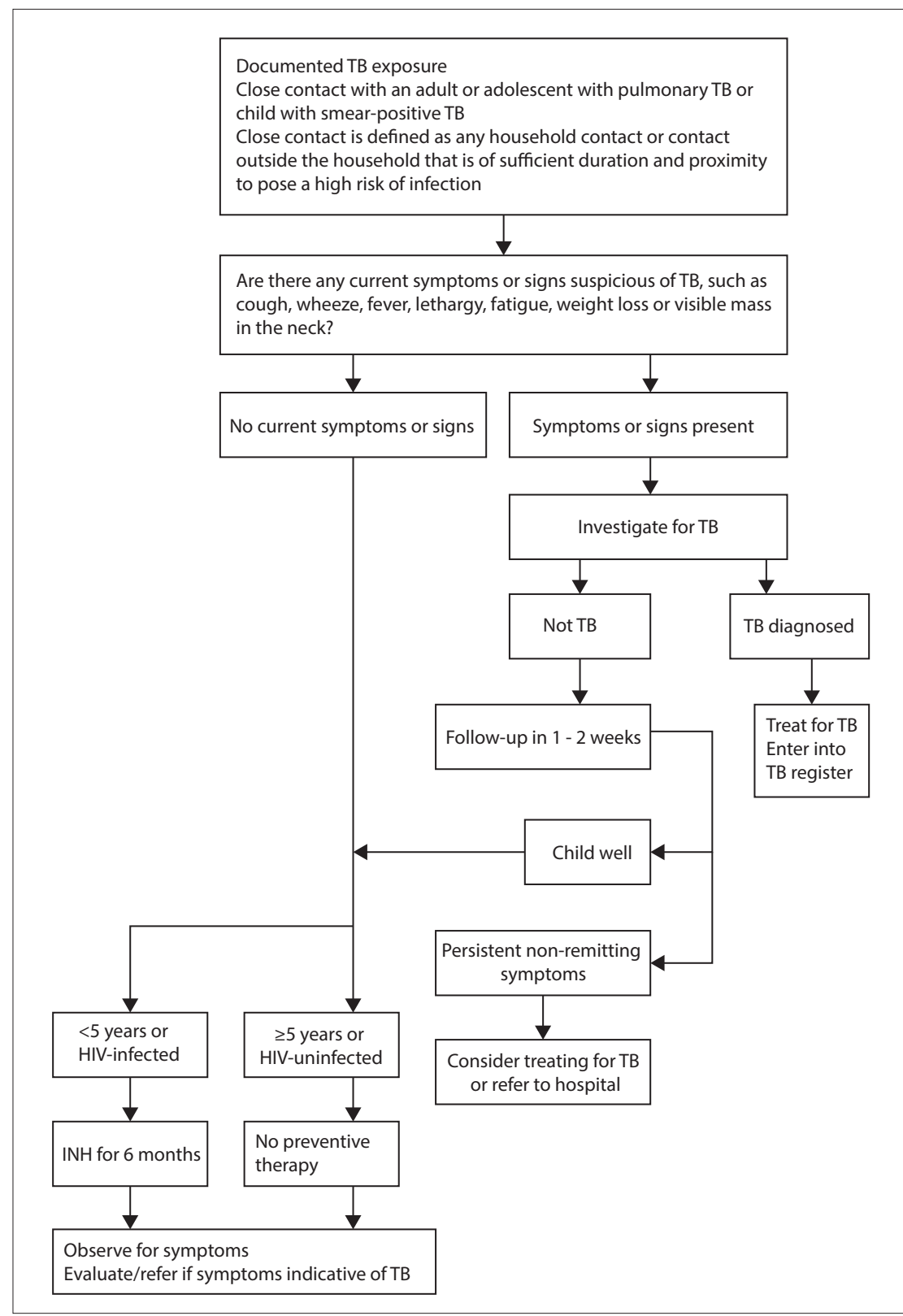

Fig. 1. Flow diagram for screening a child with documented tuberculosis exposure. (TB = tuberculosis; INH $=$ isoniazid. $)^{[21]}$

transport costs and delays in test results were found to impede IPT delivery, ${ }^{[17]}$ while in an Indian study the lack of healthcare worker knowledge and awareness about IPT were reasons for poor IPT implementation. ${ }^{[16]}$ Qualitative studies in Cape Town have shown that barriers to a successful IPT programme included health systems issues, such as staff shortages and patient- and communityrelated factors, including poverty, stigma and parents' resistance to treatment. ${ }^{[20]}$ The successful implementation of child contact screening and management is hampered by a variety of challenges and barriers unique to each setting. ${ }^{[7]}$ Information regarding IPT services in the Eastern Cape and NMBHD is lacking, with no baseline data. Identifying problem areas in child contact management within the $\mathrm{TB}$ programme may help to reduce childhood $\mathrm{TB}$ and ultimately assist in curbing the expanding TB epidemic.

The hypothesis of this study was that child contacts $<5$ years of age are not routinely identified, screened and administered IPT and that there is a large drop-out rate of children who start IPT.

The objectives of this study were to assess: - whether child $\mathrm{TB}$ contacts are being identified, screened and managed according to the $\mathrm{NDoH} \mathrm{TB}$ control programme guidelines at a single primary healthcare facility in NMBHD

- the proportion of children who completed the required course of $\mathrm{TB}$ preventive medication
- whether the age, gender, education and employment status of the index cases and their disease characteristics (HIV status, smear positivity and previous $\mathrm{TB}$ ) relate to the documentation of child contacts, their screening and initiation of IPT.

\section{Methods}

This cross-sectional descriptive study was conducted at a primary healthcare clinic in the NMBHD, one of eight health districts in the Eastern Cape Province, SA. The district has a population of $\sim 1.2$ million, with children $<5$ years of age accounting for $\sim 10 \%$. In 2012, the TB incidence in NMBHD was reported as $949.3 / 100000,{ }^{[4]}$ with $16 \%$ of cases in children $<19$ years of age and those aged $<5$ years accounting for $7.2 \%$ of the total case number. ${ }^{[3]}$ The annual TB case load at the study site was $\sim 300$ (Ms B Ncanywa - personal communication, 2014). A retrospective record review using information collected by clinic staff during routine care of patients was conducted.

Information regarding contacts should be routinely recorded at the back of each TB patient's treatment card (name, surname, age, whether contacts were screened and if IPT or TB treatment was started). Eligible child contacts are screened. In those in whom active TB disease has been excluded, a 6-month course of IPT should be given. ${ }^{[19,21,22]}$ IPT is dispensed monthly and is recorded on a dedicated IPT card filed in the TB room.

Adult index patients who started TB treatment between 21 October 2011 and 28 February 2014 were included. As per the literature and in line with WHO standards, an adult TB patient was defined as being $>15$ years of age..$^{[1,13,16,23]}$ Child contacts were defined as children $<5$ years of age, who are in close contact with an adult with infectious TB. ${ }^{[2,22]}$ Only index patients with bacteriologically confirmed pulmonary TB were enrolled. These are patients with smear and/or GeneXpert (Cepheid, USA) and/or culture-positive sputum results, including drug-sensitive and drug-resistant pulmonary TB disease. HIV status was not recorded on the IPT card; therefore, any child contact $>5$ years old, regardless of HIV status, was not included in the study. Completion of IPT treatment was defined as a contact having collected at least 24 weeks of IPT. If a contact was discharged after 6 months of treatment, but had not collected medication for the relevant time period, they were not classified as having completed treatment.

A similar study in a high-TB-burden setting established that $20 \%$ of eligible child contacts were initiated on IPT. ${ }^{[13]}$ This figure was used to calculate the sample size of 246 child contacts, which was required to obtain a $95 \%$ 
confidence interval (CI) with a $5 \%$ precision, using EpiCalc 2000 (Microsoft, USA). ${ }^{[24]}$

Index patients were identified from the drug-sensitive $\mathrm{TB}$ treatment register and folders in the TB filing system at the clinic. Folders of all eligible index patients who started TB treatment at the clinic from 21 October 2011 to 28 February 2014 were reviewed, together with all IPT cards for children who started therapy during this period. An attempt was made to link these contacts to an index case. Both drugsensitive and drug-resistant index patients were enrolled. In line with $\mathrm{NDoH}$ and $\mathrm{WHO}$ guidelines, contacts of multidrug-resistant $\mathrm{TB}$ are not administered second-line TB drugs for prophylaxis. ${ }^{[2,22,25]}$ According to local practice, these contacts are managed at primary clinic level in the same way as contacts of drug-sensitive patients ( $\mathrm{Sr} N$ Geswint - personal communication, 2014).

An adapted data collection tool based on that of Osman et al. ${ }^{[15]}$ was used to record information relating to the identification of child contacts, the index patient demographics and disease characteristics, as well as the clinical management of contacts receiving IPT. Data were entered into Microsoft Excel 2010 (Microsoft, USA) and analysed using statistical programme R (R Foundation for Statistical Computing, Austria). ${ }^{[26]}$

\section{Ethical approval}

In accordance with the principles of good clinical practice, permission to conduct the study was obtained from the Human Research Ethics Committee of the University of Cape Town (ref. no. HREC REF 345/2014). Approval was also obtained from the Eastern Cape Health Department and the NMBHD TB directorate to conduct research in the area.

\section{Results}

From 21 October 2011 to 28 February 2014, 690 patients were recorded in the TB register at the clinic. These included children and adults with pulmonary and extrapulmonary disease. Folders of 491 index patients who met the inclusion criteria were in the filing system and reviewed. A total of 261 child contacts were identified from 474 drugsensitive and 17 drug-resistant index cases. More than half of the index patients were men (54\%) and the index patients' mean (standard deviation (SD)) age was 36.6 (13.4) years. Unemployment rates in the area were high, with $56 \%$ of index patients not working. Almost $97 \%$ of index patients were tested for HIV; $78 \%$ were negative.

Of the 491 index patient folders, 61 (12.5\%) had no documentation relating to contacts of any age, and 261 child contacts were identified (Fig. 2). Six were excluded from the analysis owing to no age being recorded - only the word 'child'. The mean number of contacts of any age identified was 3.6 (2.9) and a mean of $0.53(0.8)$ child contacts were identified per index patient. The mean age of child contacts was 2.25 (1.3) years (range 1 month - 5 years).

Of the 261 child contacts identified, $70.5 \%$ $(n=184)$ were screened for TB using one or more of the following: symptom screen, tuberculin skin test (TST), chest radiograph, gastric washing or sputum and referral for further management. The most common methods of screening included a symptom screen $(n=111 ; 60.3 \%)$ and/or a TST $(n=145$; $78.7 \%)$. Of those who had a TST, almost half $(47.6 \%)$ did not have a documented symptom screen prior to the TST being done, as is recommended in the $\mathrm{NDoH}$ guidelines. ${ }^{[21,22]}$

Only 2 (1\%) of the 184 patients screened were known to have started treatment for TB disease, although in many cases $(n=74$; $40.2 \%)$ there was no documentation of whether TB treatment or IPT was initiated. Of the initial 255 contacts, $56.8 \% \quad(n=145)$ had no documentation of initiation of any therapy - preventive or other. One hundred and eight (58.7\%; CI \pm 7.11 ) contacts were documented on the index case folder as having started TB preventive therapy, but only $74(68.5 \%)$ IPT cards were found for patients who commenced IPT treatment during this period.

On 7 IPT cards, the index patient's name was not recorded. There were such cards for 9 contacts who were not eligible for IPT, either owing to the contact's age (3 were $>5$ years) or to the disease characteristics of the index patient (there were 6 cards for contacts of index patients who had sputumnegative or extrapulmonary $\mathrm{TB}$ ). These contacts were excluded from the analysis.

The majority $(91.8 \%)$ of child contacts who started TB preventive therapy were given isoniazid (INH). The drugs used for the remaining $8 \%$ were not documented. There was documentation of side-effects, routine symptom screens and weight checks on only 1 IPT card.

The median (interquartile range (IQR)) number of weeks of IPT collection was 8 (11.25). Of those who started IPT, 10 children were reported to have completed 6 months

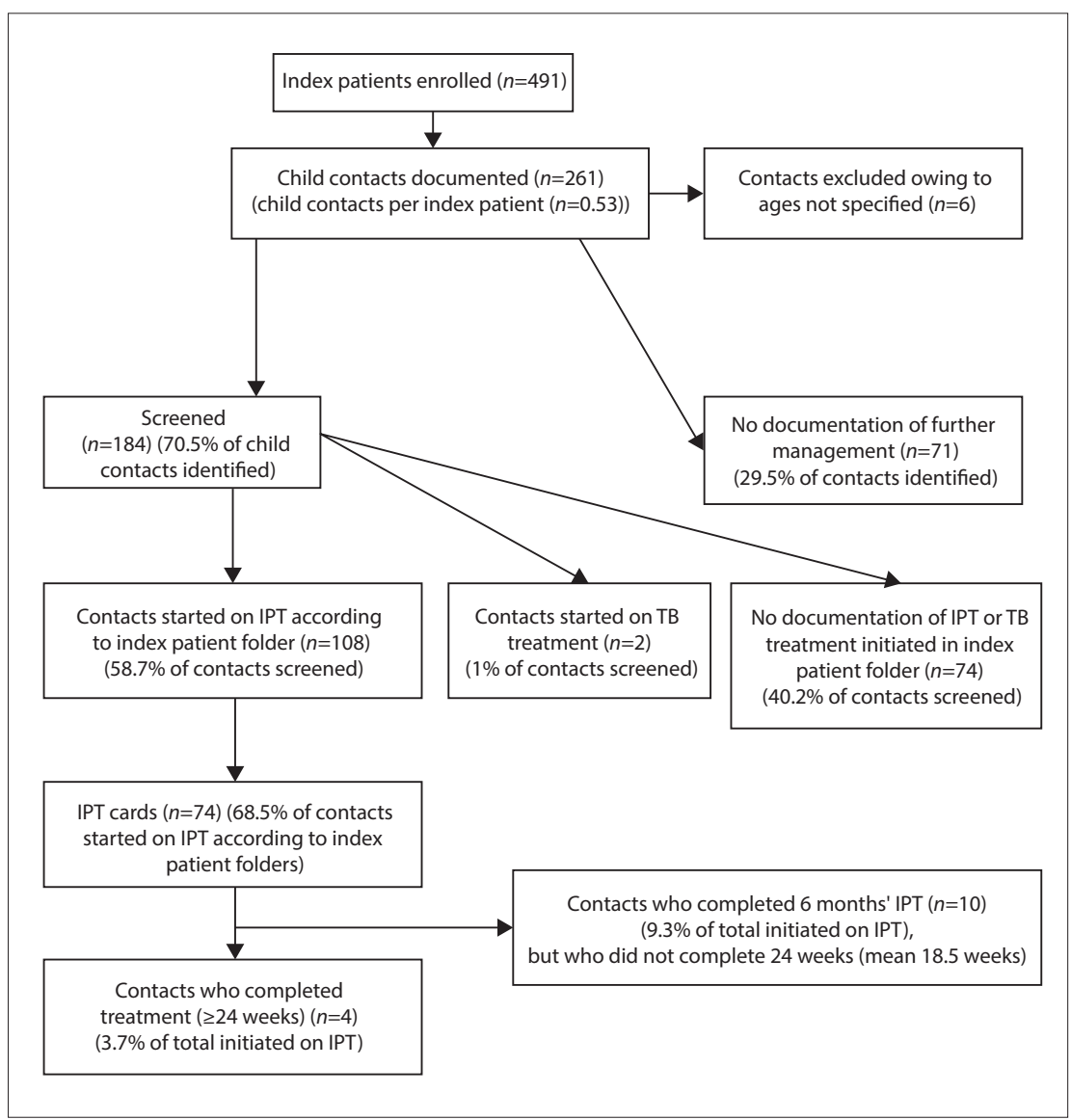

Fig. 2. Flow diagram of child contacts, from identification to treatment completion. $(T B=$ tuberculosis; $I P T=$ isoniazid preventive therapy.) 
of treatment, but they had not received IPT for varying lengths of time during this period; therefore, the actual number of weeks of IPT appeared shorter (mean 18.5 (2.83)). Only 4 children (3.7\%; CI $\pm 3.56)$ completed the 24 -week course. Fig. 3 depicts this decay from identification to IPT completion.

$\chi^{2}$ tests were used to establish the relationship between the index patient's demographics (age, gender, employment status), their

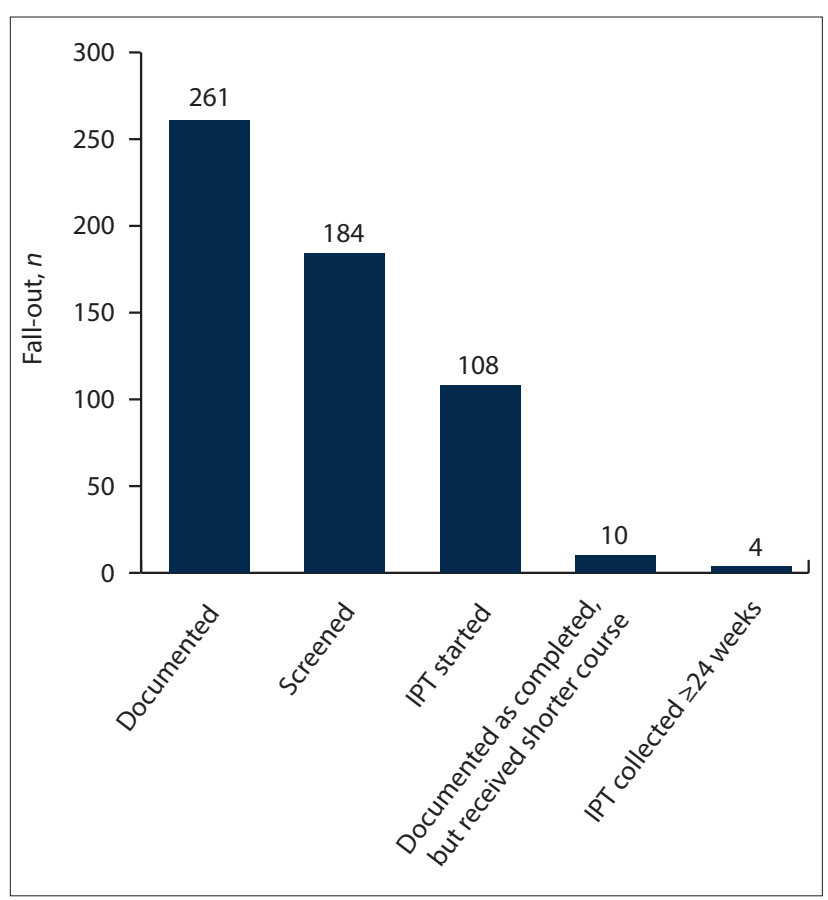

Fig. 3. Fall-out of child contacts, from identification to treatment completion. (IPT $=$ isoniazid preventive therapy.) disease characteristics (HIV status, smear positivity and previous TB) and the identification and management of child contacts. Tables 1 - 3 show the results of these analyses. Of statistical significance is that documentation of child contacts for male index patients $(p=0.01)$ was less likely. Male patients $(p=0.003)$ and those who were retreated for TB ( $p=0.01$ ) were less likely to bring their contacts for screening. Child contacts of index patients retreated for TB were less likely to initiate IPT $(p=0.04)$.

\section{Discussion}

Contact identification was well reported in index patient folders. Only $12.5 \%$ of patient folders had no documentation of contacts. However, the number of child contacts per index patient (mean 0.53 (0.8)) was lower than that in previous studies $(0.7-1.3$ child contacts per infectious TB case). ${ }^{[11-15]}$ The study site relies on passive contact tracing, i.e. index patients are requested to bring their contacts to the clinic for screening; they are not actively traced by a healthcare worker. Although active contact tracing has been shown to yield substantially more TB cases, ${ }^{[17]}$ it is only the first of many steps, including appropriate management of infectious patients, as well as diligent supervision of child contacts, required to prevent TB in children. The screening process, IPT initiation and follow-up in children are considerable hurdles in TB preventive programmes. ${ }^{[15]}$

Of the 255 contacts included in the analysis, $72 \%(n=184)$ were screened for active TB disease. Although this is higher than that found in a previous study $(42 \%),{ }^{[15]}$ the opportunity to screen young children was missed in more than a quarter of child contacts identified. This could relate to the problem of passive case finding.

The majority of children (79\%) were screened using a TST. Of those thus screened, for almost half (48\%) there was no documentation of a symptom screen. This practice does not follow the $\mathrm{NDoH} \mathrm{TB}$ control programme screening protocol in either the 2009 or 2013 guidelines. ${ }^{[21,22]}$ These guidelines state that investigations should be

Table 1. Relationship between index patient demographic factors and disease characteristics and child contacts $<5$ years of age

\begin{tabular}{|c|c|c|c|c|c|}
\hline Demographic factors & Records analysed, $n$ & $\begin{array}{l}\text { Records with child cor } \\
<5 \text { years of age, } n(\%)\end{array}$ & $\chi^{2}$ & Odds ratio( $95 \% \mathrm{CI})$ & $p$-value \\
\hline \multicolumn{6}{|l|}{$\operatorname{Gender}^{*}(n=490)$} \\
\hline Male & 264 & $100(37.9)$ & 7.31 & $0.60(0.42-0.86)$ & 0.01 \\
\hline Female & 226 & $114(50.4)$ & & & \\
\hline \multicolumn{6}{|l|}{ Age, years* $(n=490)$} \\
\hline$\leq 35$ & 247 & $117(47.4)$ & 2.47 & $1.35(0.95-1.94)$ & 0.12 \\
\hline$>35$ & 243 & $97(39.9)$ & & & \\
\hline \multicolumn{6}{|l|}{$\begin{array}{l}\text { Employment status }^{\dagger} \\
(n=437)\end{array}$} \\
\hline Employed & 163 & $79(48.5)$ & 1.49 & $1.30(0.88-1.92)$ & 0.22 \\
\hline Unemployed & 274 & $115(42.0)$ & & & \\
\hline \multicolumn{6}{|l|}{ HIV status $(n=475)$} \\
\hline Infected & 93 & $40(43.0)$ & 0.00 & $0.96(0.61-1.52)$ & 0.96 \\
\hline Uninfected & 382 & $168(44.0)$ & & & \\
\hline \multicolumn{6}{|l|}{ Previous TB ${ }^{\ddagger}(n=483)$} \\
\hline Yes & 137 & $67(48.9)$ & 1.83 & $1.34(0.9-2.0)$ & 0.18 \\
\hline No & 346 & $144(41.6)$ & & & \\
\hline \multicolumn{6}{|l|}{ Smear status ${ }^{\S}(n=478)$} \\
\hline Positive & 383 & $176(45.9)$ & 2.78 & $1.52(0.96-2.43)$ & 0.095 \\
\hline Negative & 95 & $34(35.8)$ & & & \\
\hline \multicolumn{6}{|c|}{$\begin{array}{l}\text { CI = confidence interval. } \\
{ }^{*} n=490 \text { (not } n=491 \text { ) due to missing data required for analysis. } \\
\text { 'Excluding pensioners, students and 'unknown. } \\
\text { "Excluding unknown. } \\
\text { 'Excluding 'not done' and 'not documented'. }\end{array}$} \\
\hline
\end{tabular}


Table 2. Relationship between index patient demographic factors and disease characteristics and child contacts $<5$ years of age screened

\begin{tabular}{|c|c|c|c|c|c|}
\hline Demographic factors & Records analysed, $n$ & $\begin{array}{l}\text { Records with documentation of } \\
\text { contact screening, } n(\%)\end{array}$ & $\chi^{2}$ & Odds ratio $(95 \% \mathrm{CI})$ & $p$-value \\
\hline \multicolumn{6}{|l|}{ Gender $^{*}(n=255)$} \\
\hline Male & 104 & $64(61.5)$ & \multirow{2}{*}{8.98} & \multirow{2}{*}{$0.41(0.24-0.72)$} & \multirow{2}{*}{0.003} \\
\hline Female & 151 & $120(79.5)$ & & & \\
\hline \multicolumn{6}{|l|}{ Age, years ${ }^{\star}(n=255)$} \\
\hline$\leq 35$ & 160 & $118(73.7)$ & \multirow{2}{*}{0.35} & \multirow{2}{*}{$1.23(0.7-2.16)$} & \multirow{2}{*}{0.55} \\
\hline$>35$ & 95 & $66(69.4)$ & & & \\
\hline \multicolumn{6}{|c|}{ Employment status $^{\dagger}(n=232)$} \\
\hline Employed & 91 & $67(73.6)$ & \multirow{2}{*}{0.09} & \multirow{2}{*}{$1.14(0.63-2.07)$} & \multirow{2}{*}{0.77} \\
\hline Unemployed & 141 & $100(70.9)$ & & & \\
\hline \multicolumn{6}{|l|}{ HIV status ${ }^{\ddagger}(n=246)$} \\
\hline Infected & 50 & $36(72.0)$ & \multirow{2}{*}{0.00} & \multirow{2}{*}{$1.02(0.52-2.05)$} & \multirow{2}{*}{1.00} \\
\hline Uninfected & 196 & $140(71.5)$ & & & \\
\hline \multicolumn{6}{|l|}{ Previous $\mathrm{TB}^{\ddagger}(n=251)$} \\
\hline Yes & 73 & $44(60.2)$ & \multirow{2}{*}{6.37} & \multirow{2}{*}{$0.45(0.25-0.81)$} & \multirow{2}{*}{0.01} \\
\hline No & 178 & $137(76.9)$ & & & \\
\hline \multicolumn{6}{|l|}{ Smear status $^{\S}(n=249)$} \\
\hline Positive & 208 & $152(73.0)$ & \multirow{2}{*}{0.56} & \multirow{2}{*}{$1.40(0.69-2.88)$} & \multirow{2}{*}{0.45} \\
\hline Negative & 41 & $27(65.8)$ & & & \\
\hline \multicolumn{6}{|c|}{$\begin{array}{l}\mathrm{CI}=\text { confidence interval. } \\
{ }^{*} n=255 \text { (not } n=261 \text { ) due to missing data required in analysis. } \\
\text { 'Excluding pensioners, toudents and 'unknown'. } \\
\text { "Excluding unknown. } \\
\text { 'Excluding 'not done' and 'not documented. }\end{array}$} \\
\hline
\end{tabular}

Table 3. Relationship between index patient demographic factors and disease characteristics and child contacts $<5$ years of age initiated on IPT

\begin{tabular}{|c|c|c|c|c|c|}
\hline Demographic factors & Records analysed, $n$ & $\begin{array}{l}\text { Records with documenta- } \\
\text { tion of IPT initiated, } n(\%)\end{array}$ & $\chi^{2}$ & Odds ratio $(95 \% \mathrm{CI})$ & $p$-value \\
\hline \multicolumn{6}{|l|}{ Gender $^{*}(n=253)$} \\
\hline Male & 104 & $42(40.4)$ & 0.24 & $0.85(0.51-1.42)$ & 0.62 \\
\hline Female & 149 & $66(44.3)$ & & & \\
\hline \multicolumn{6}{|l|}{ Age, years ${ }^{\star}(n=253)$} \\
\hline$\leq 35$ & 159 & $71(44.6)$ & 0.48 & $1.24(0.74-2.09)$ & 0.49 \\
\hline$>35$ & 94 & $37(39.4)$ & & & \\
\hline \multicolumn{6}{|c|}{ Employment status $^{\dagger}(n=230)$} \\
\hline Employed & 91 & $46(50.5)$ & 3.36 & $1.71(1.0-2.92)$ & 0.07 \\
\hline Unemployed & 139 & $52(37.4)$ & & & \\
\hline \multicolumn{6}{|l|}{ HIV status ${ }^{\ddagger}(n=244)$} \\
\hline Infected & 50 & $21(42)$ & 0.0 & $0.99(0.53-1.86)$ & 1.0 \\
\hline Uninfected & 194 & $82(42.2)$ & & & \\
\hline \multicolumn{6}{|l|}{ Previous TB $\mathrm{TB}^{\ddagger}(n=249)$} \\
\hline Yes & 73 & $24(32.8)$ & 4.05 & $0.54(0.3-0.95)$ & 0.04 \\
\hline No & 176 & $84(47.7)$ & & & \\
\hline \multicolumn{6}{|l|}{ Smear status ${ }^{\S}(n=247)$} \\
\hline Positive & 206 & $90(43.7)$ & 0.46 & $1.34(0.67-2.69)$ & 0.50 \\
\hline Negative & 41 & $15(36.6)$ & & & \\
\hline \multicolumn{6}{|c|}{$\begin{array}{l}\text { IPT = isoniazid preventive therapy; } \mathrm{CI}=\text { confidence interval. } \\
{ }^{*} n=253 \text { (not } n=261 \text { ) due to missing data required for the analysis. } \\
\text { 'Employment status excluding pensioners, students and 'unknown. } \\
\text { 'Excluding 'unknown'. } \\
\text { 'Excluding 'not doneand 'not documented'. }\end{array}$} \\
\hline
\end{tabular}

performed only if a symptom screen is positive. There is little value in performing a TST in a recently exposed, asymptomatic child, given that the delayed-type hypersensitivity may take up to 3 months to develop. ${ }^{[27]}$ Children who are exposed to an infectious adult with TB and are asymptomatic, require IPT regardless of the TST result. A TST is of greater value when attempting to confirm a diagnosis of TB disease in a sick child, although even then it can be falsely negative in a subgroup of patients who have severe disease or are immunocompromised. ${ }^{[27]}$

The 'no test' screening method has been shown to be the most costeffective technique in young children exposed to TB. ${ }^{[28]}$ Unavailability of tuberculin, lack of staff expertise to interpret test results, additional transport costs, time required to complete the screening process and increased staff workload have all been described as barriers to IPT 
delivery. ${ }^{[29]}$ The lack of a TST and chest radiography should not be a barrier to child contact screening and management. ${ }^{[25,30]}$

Of the 184 children who were screened, 59\% $(n=108)$ were documented as having started IPT, 2 started full TB treatment and for $40 \%(n=74)$ there was no documentation of further management or follow-up. The last represents missed opportunities for providing TB preventive therapy in a community where TB is rife. Due to the lack of documentation in patient folders, it was not possible to determine whether the caregivers of these children were offered IPT and declined, or whether IPT was never prescribed. Caregivers' perception that a child who is well does not need medication, interfered with IPT provision in previous studies. ${ }^{[1,18,19]}$ This perception, compounded by the system of passive contact tracing, could have a significant negative effect on IPT provision in this setting. The fall-out of child contacts could also relate to the screening methods used. In this low-income setting, patients may be unable to afford to return for TST results and chest radiographs, with consequent loss of followup. Additional barriers to initiation of and adherence to IPT include stigma related to $\mathrm{TB}$, community misconceptions around the role of IPT and social problems, such as substance abuse and domestic violence. $^{[20]}$

There were 74 IPT cards for children starting IPT during the study period, which represents $69 \%$ of those who started preventive therapy and $40 \%$ of the total number who were screened. There were 9 IPT cards for 9 children who started IPT, who were either $>5$ years of age or who were contacts of non-bacteriologically confirmed pulmonary or extrapulmonary $\mathrm{TB}$ index patients. This showed a deviation from the $\mathrm{NDoH} \mathrm{TB}$ control programme protocol, which states that only contacts of index patients with bacteriologically confirmed pulmonary TB who are $<5$ years of age are eligible for IPT. Children $>5$ years of age are eligible if they are HIV-infected. ${ }^{[21,22]}$ There was no documentation of the HIV status for children $>5$ years of age, as mentioned above. Also, there were 7 cards with poor or no documentation of the index patient's name, precluding assessment of these contacts.

The number of IPT cards found may be an under-representation of the actual number of existing cards. Firstly, the filing system was inefficient and not user friendly, mostly owing to a lack of accessible filing space in the clinic. Secondly, it was sometimes difficult to link the IPT card and the index patient.

The IPT card system attempted to formalise the provision of IPT in the district. The WHO, however, recommends the use of a dedicated IPT register in which to document household contacts details. ${ }^{[25]}$ The positive effects of such a system were demonstrated by studies in India ${ }^{[31]}$ and Cape Town, ${ }^{[32]}$ with more contacts being identified and initiated on IPT, better documentation of information and improved adherence rates. A register may resolve the problems experienced with the disorganised IPT card filing system, allowing easier monitoring of the programme.

Improvements could be made to the system. The index patient register number and sputum drug sensitivities should also be documented on the IPT card to link the contact and index case and adjust management accordingly. For example, the NDoH TB control programme guidelines recommend a 4-month rifampicin course instead of a 6-month INH course as preventive therapy in INH-resistant index patients. ${ }^{[22]}$ Furthermore, the HIV status of the contact should be recorded. HIV-infected children are at extremely high risk of developing TB disease, ${ }^{[33]}$ and all HIV-infected children, regardless of age, should be administered IPT after exposure to a known bacteriologically confirmed pulmonary TB case. ${ }^{[22]}$

There was no routine documentation of symptom checks or repeat weight checks at subsequent visits to collect IPT. The importance of this is twofold. Firstly, to detect TB disease in children, ${ }^{[22,32]}$ and, secondly, to increase the dose of INH according to the increasing weight of the child to maintain an effective dose throughout treatment. Side-effects of IPT were never documented on the audited IPT cards. Although side-effects from INH are uncommon, addressing even minor ones and re-assuring caregivers may improve retention of contacts receiving IPT. ${ }^{[34]}$

The WHO and NDoH recommend a 6-month course of INH to prevent $\mathrm{TB}$ in child contacts; ${ }^{[22,25]}$ however, adherence rates are poor with this regimen. ${ }^{[10,11,15]}$ Contacts in this study collected IPT for a median (IQR) number of 8 (11.25) weeks. Only 4 (3.7\%) contacts completed the course. Some contacts completed 6 months of treatment during the relevant time, but had collected INH for $<24$ weeks. These missed doses may have been the result of poor patient compliance or because of INH stock-outs (Sr N Geswint personal communication, 2014). Compliance with shorter courses of TB preventive therapy, i.e. 3- or 4-month courses of INH/rifampicin or rifampicin alone, is significantly better ${ }^{[10,35,36]}$ and should be considered in SA.

Results indicated that child contacts of male index patients and index patients with a previous history of TB are at high risk of poor management. Osman et al. ${ }^{[15]}$ demonstrated similar results in Cape Town. In general, male TB patients have been shown to delay seeking medical attention and are more likely to default their treatment than female TB patients. ${ }^{[37]}$ This type of health-seeking behaviour could negatively impact the care of child contacts. These index patients should be earmarked for more attentive consultations and in-depth counselling regarding their disease and the risk it poses to their contacts.

\section{Study limitations}

This study has a number of important limitations. It relied on data collected from patient files. As with all record reviews, a major limitation is missing information. ${ }^{[38]}$ The study only took into account patients who started TB treatment. It did not account for patients who were diagnosed with $\mathrm{TB}$, but defaulted treatment initiation, or those who defaulted after transfer from a hospital. Therefore, the number of child contacts initiated on IPT is an under-representation of the number of child contacts who should have received IPT. The study design did not allow for the assessment of the uptake of IPT by caregivers. Caregivers' refusal to medicate has been shown to be a significant barrier to providing children with IPT. ${ }^{[20]}$

\section{Conclusion}

The appropriate management of child TB contacts is essential to reduce the burden of disease in children. The results of this study demonstrate inadequate child contact tracing and significant fall-out of children at various time points in the contact screening-treatment continuum. The findings emphasise that documentation is poor, and that deviation from protocols is common. Operational challenges such as a suboptimal recording tool and a disorganised filing system contribute to these outcomes. Staff- and patient-related factors may, however, also play a role. Although this study was conducted at a single site, the problem of poor contact management is likely to be pervasive throughout other areas in the district.

The improvement of $\mathrm{TB}$ contact tracing and management requires consolidated buy-in and increased commitment from all stakeholders, including the community. Recommendations for the $\mathrm{NDoH}$ include a review of the national IPT guidelines, taking into account the relative success of shorter courses of TB prophylaxis. The use of standardised IPT stationery, including a register and patient appointment cards, could improve filing and follow-up systems. Information with regard 
to the HIV status of the child, the index patient register number and drug sensitivities should be included in the register. Provincial and district level recommendations pertain to the inclusion of indicators related to child IPT in the quarterly reports requested by the NDoH. Regular staff training and evaluation, adequate support and active involvement of community health workers in contact tracing and monitoring may improve outcomes. Further research is required in the management of child contacts of drug-resistant TB patients, as well as the qualitative aspects of barriers or perceived barriers relating to patient, healthcare worker and operational challenges that hinder the delivery of IPT to children in this setting.

Acknowledgements. Dr V Goodall, Nelson Mandela Bay University, for assistance with statistical evaluation; and Sr L Sookdin and her staff at the research site for their assistance with filing and data collection.

Author contributions. FB: principal author; JS and FA: supervision of research and review of the manuscript.

Funding. This publication was made possible by funding from the University of Cape Town.

Conflicts of interest. None.

1. World Health Organization. Global Tuberculosis Report, 2016. Geneva: WHO, 2016 2. World Health Organization. Global Tuberculosis Report, 2014. Geneva: WHO, 2014

3. Smith J, Moyo S, Day C. A review of TB in children and adolescents in South Africa 2008 - 2012. In: Padarath A, English R, eds. South African Health Review 2013/14. Durban: Health Systems Trust, 2014.

4. Loveday M, Smith J, Day C. Knowing our TB epidemic: Key challenges facing the TB programme in South Africa. In: Padarath A, English R, eds. South African Health Review 2013/14. Durban: Health Systems Trust, 2014.

5. Graham SM, Sismanidis C, Menzies HJ, Marais BJ, Detjen AK, Black RE. Importance of tuberculosis 5raham SM, Sismanidis C, Menzies HJ, Marais B], Detjen AK, Black RE. Importance of tuberculosis
control to address child survival. Lancet 2014;383(9928):1605-1607. https://doi.org/10.1016/S0140control to address

6. Marais BJ, Gie RP, Schaaf HS, et al. The clinical epidemiology of childhood pulmonary tuberculosis: A critical review of literature from the pre-chemotherapy era. Int J Tuberc Lung Dis 2004;8(3):278-285. 7. Graham SM, Triasih R. More evidence to support screening of child contacts of tuberculosis cases: If not now, then when? Clin Infect Dis 2013;57(12):1693-1694. https://doi.org/10.1093/cid/cit647

8. Ayieko J, Abuogi L, Simchowitz B, Bukusi EA, Smith AH, Reingold A. Efficacy of isoniazid prophylactic therapy in prevention of tuberculosis in children: A meta-analysis. BMC Infect Dis 2014;14(91):1-10. https://doi.org/10.1186/1471-2334-14-9

9. National Department of Health. The South African National Tuberculosis Control Programme Practical Guidelines 2004. http://www.kznhealth.gov.za/chrp/documents/Guidelines/Guidelines National/ Tuberculosis/SA TB Guidelines 2004.pdf (accessed 14 July 2017).

10. Van Zyl S, Marais BJ, Hesseling AC, Gie RP, Beyers N, Schaaf HS. Adherence to anti-tuberculosis chemoprophylaxis and treatment in children. Int J Tuberc Lung Dis 2006;10(1):13-18.

11. Marais BJ, van Zyl S, Schaaf HS, van Aardt M, Gie RP, Beyers N. Adherence to isoniazid preventive chemotherapy: A prospective community based study. Arch Dis Child 2006;91:762-765. https://doi. chemotherapy: A prospective
org/10.1136/adc. 2006.097220

12. Schaaf HS, Marais BJ, Whitelaw A, et al. Culture-confirmed childhood tuberculosis in Cape Town, South Africa: A review of 596 cases. BMC Infect Dis 2007;7:140. https://doi.org/10.1186/1471-2334-7-140

13. Van Wyk SS, Hamade H, Hesseling AC, Beyers N, Enarson DA, Mandalakas AM. Recording isoniazid preventive therapy delivery to children: Operational challenges. Int J Tuberc Lung Dis 2010;14(5):650-653.
pring 14. Du Preez K, Hesseling AC, Mandalakas AM, Marais BJ, Schaaf HS. Opportunities for chemoprophylaxis in children with culture-confirmed tuberculosis. Ann Trop Paediatr 2011;31(4):301-310. https://doi.org/10.1 179/1465328111Y.0000000035

15. Osman M, Hesseling AC, Beyers N, et al. Public health action routine programmatic delivery of isoniazid preventive therapy to children in Cape Town, South Africa: Internatonal Union Against Tuberculosis and Lung Disease health solutions for the poor. Public Health Action 2013;3(3):199-203. https://doi.org/10.5588/pha.13.0034
16. Banu Rekha VV, Jagarajamma K, Wares F, Chandrasekaran V, Swaminathan S. Contact screening and chemoprophylaxis in India’s revised tuberculosis control programme: A situational analysis. Int J Tuberc Lung Dis 2009;13(12):1507-1512.

17. Zachariah R, Spielmann M-P, Harries AD, et al. Passive versus active tuberculosis case finding and Zachariah R, Spielmann M-P, Harries AD, et al. Passive versus active tuberculosis case finding and
isoniazid preventive therapy among household contacts in a rural district of Malawi. Int J Tuberc Lung Dis 2003; $7(11): 1033-1039$.

18. Rutherford ME, Ruslami R, Maharani W, et al. Adherence to isoniazid preventive therapy in Indonesian children: A quantitative and qualitative investigation. BMC Res Notes 2012;5(7):1-7. https://doi.org/10.1186/1756-0500-5-7

19. Garie KT, Yassin MA, Cuevas LE. Lack of adherence to isoniazid chemoprophylaxis in children in contact with adults with tuberculosis in Southern Ethiopia. PLOS ONE 2011;6(11):1-4. https://doi. org/10.1371/journal.pone.0026452

20. Skinner D, Hesseling AC, Francis C, Mandalakas AM. It's hard work , but it's worth it: The task of keeping children adherent to isoniazid preventive therapy. Public Health Action 2013;3(3):191-198. https://doi.org/10.5588/pha.13.0010

21. National Department of Health. National Tuberculosis Management Guidelines. 2009. http:// familymedicine.ukzn.ac.za/Libraries/Guidelines_Protocols/TB_Guidelines_2009.sflb.ashx (accessed 7 February 2018).

22. National Department of Health. Guidelines for the Management of Tuberculosis in Children. Pretoria: $\mathrm{NDoH}, 2013$.

23. Van Wyk SS, Reid AJ, Mandalakas AM, et al. Operational challenges in managing isoniazid preventive therapy in child contacts: A high-burden setting perspective. BMC Public Health 2011;11:544. https:/ doi.org/10.1186/1471-2458-11-544

24. EpiCalc. Statistics calculator. http://epicalc-2000.software.informer.com/1.0/ (accessed 22 January 2018) 25. World Health Organization. Guidance for National Tuberculosis Programmes on the Management of Tuberculosis in Children. Geneva: WHO, 2006

26. R Core Team. A language and environment for statistical computing. http://www.r-project.org/ (accessed 7 February 2018).

27. Khan EA, Starke JR. Diagnosis of tuberculosis in children: Increased need for better methods. Emerg Infect Dis 1995;1(4):115-123. https://doi.org/10.3201/eid0104.950402

28. Mandalakas AM, Hesseling AC, Gie RP, Schaaf HS, Marais BJ, Sinanovic E. Modelling the costeffectiveness of strategies to prevent tuberculosis in child contacts in a high-burden setting. Thorax 2013;68(3):247-255. https://doi.org/10.1136/thoraxjnl-2011-200933

29. Rutherford ME, Hill PC, Triasih R, Sinfield R, van Crevel R, Graham SM. Preventive therapy in children exposed to Mycobacterium tuberculosis: Problems and solutions. Trop Med Int Health 2012;17(10):1264-1273. https://doi.org/10.1111/j.1365-3156.2012.03053.x

30. Triasih R, Robertson CF, Duke T, Graham SM. A prospective evaluation of the symptom-based Triasih R, Robertson $\mathrm{CF}$, Duke $\mathrm{T}$, Graham $\mathrm{SM}$. A prospective evaluation of the symptom-based
screening approach to the management of children who are contacts of tuberculosis cases. Clin Infect Dis 2015;60:12-18. https://doi.org/10.1093/cid/ciu748

31. Rekha B, Jagarajamma K, Chandrasekaran V, Wares F, Sivanandham R, Swaminathan S. Improving screening and chemoprophylaxis among child contacts in India’s RNTCP: A pilot study. Int J Tuberc Lung Dis 2013;17(2):163-168. https://doi.org/10.5588/ijtld.12.0415

32. Van Soelen N, du Preez K, van Wyk SS, et al. Does an isoniazid prophylaxis register improve tuberculosis contact management in South African children? PLOS ONE 2013;8(12):e80803. https:// doi.org/10.1371/journal.pone.0080803

33. Hesseling AC, Cotton MF, Jennings T, et al. High incidence of tuberculosis among HIV-infected infants: Evidence from a South African population-based study highlights the need for improved tuberculosis control strategies. Clin Infect Dis 2009;48(8):108-114. https://doi.org/10.1086/595012

34. Pang SC, Harrison RH, Brearley J, Jegathesan V, Clayton AS. Preventive therapy for tuberculosis in Western Australia. Int J Tuberc Lung Dis 1998;2(12):984-988. https://doi.org/10.1016/s09546111(05)80349-x

35. Spyridis NP, Spyridis PG, Gelesme A, et al. The effectiveness of a 9-month regimen of isoniazid alone versus 3 - and 4 -month regimens of isoniazid plus rifampin for treatment of latent tuberculosis
als alone versus 3-and 4-month regimens of isoniazid plus rifampin for treatment of latent tuberculosis
infection in children: Results of an 11-year randomized study. Source Clin Infect Dis 2007:45(6):715infection in children: Results of an $11-y$. h22.tps://doi.org/10.1086/520983

36. Sharma S, Kadhiravan T, Tharyan P. Rifamycins (rifampicin, rifabutin and rifapentine) compared to isoniazid for preventing tuberculosis in HIV-negative people at risk of active TB. Cochrane Collab 2013; (7):1-40. https://doi.org/10.1002/ebch.1962

37. Hof S, Najilis C, Bloss E, Straetemans M. A systematic review on the role of gender in tuberculosi control. 2010. http://www.tbcarel.org/publications/toolbox/tools/access/Role_of_Gender_in_TB_Control pdf (accessed 7 February 2018)

38. Gearing RE, Mian IA, Barber J, Ickowicz A. A methodology for conducting retrospective chart review research in child and adolescent psychiatry. J Can Acad Child Adolesc Psychiat 2006;15(3):126-134. 